Institut für Makroökonomie und Konjunkturforschung Macroeconomic Policy Institute

\title{
Agent-based risk management - A regulatory approach to financial markets
}

\begin{abstract}
This paper provides market risk calculation for an equity-based trading portfolio. Instead of relying on the purely stochastic internal model method, which banks currently apply in line with the Basel regulatory requirements, we propose to include also alternative price mechanisms from the financial literature into the regulatory framework. For this purpose a modified version of the model by Lux and Marchesi (2000) is developed, capturing the realistic feature that parts of the investors do not follow the assumption of no arbitrage, but are motivated by rules of thumb and market psychology instead. Although both the standard stochastic as well as the behavioral model are restricted to 250 trading days, the latter is able to capitalize possible turbulences on financial markets and likewise the well-known phenomenon of excess volatility - even if the last 250 days reflect a calm market for which the efficient-market hypothesis could hold. Thus it is argued that a value-at-risk-based maximum approach in the regulatory framework would create better capital requirements with respect to their level and counter-cyclicality. This in turn could reduce the extent to which (irrational) bubbles arise since market participants would have to anticipate comprehensively the costs of such bubbles bursting. Furthermore a key ratio is deduced from the agent-based construction to lower the influence of speculative derivatives.
\end{abstract}

Keywords: systemic risk, behavioral finance, agent-based model, financial crisis

JEL CLASSIFICATION SYSTEM: D03, G17, G32

\footnotetext{
* Macroeconomic Policy Institute (IMK), Düsseldorf; Freie Universität (FU), Berlin
} 


\section{Introduction}

In the aftermath of the financial crisis there has been a broad societal consensus to improve financial regulation. Although different actions have been taken worldwide - the Basel III (2010) regulations, the Dodd-Frank Act and the creation of the European Systemic Risk Board (ESRB) are the most important to be mentioned - doubts remain, whether these actions have been sufficient, see for example Chappe and Semmler (2012) and Dullien (2012). One of the relatively unaffected fields are the risk management models particularly linked to the first pillar of Basel II, which allows besides a standard approach the application of the so-called internal model method (IMM). The idea behind this value-at-risk approach was to install an effective risk calculation inside banks influencing daily business strategy and creating an anchor for the supervision of the national controlling authorities. In the end, this value determines an essential part of the regulatory capital which is destined to back the different risks.

Like in other areas of economics there is a huge demand for a turnaround in financial market modeling in order to do justice to the mistakes initiating the recent crisis. Yet, one could admit that at least in academic financial literature half of the distance is covered. For instance Shiller (2003) already described a development 'From efficient market theory to behavioral finance'. Regrettably there is no parallel line within the risk management models, where still the condition of no-arbitrage among other doubtable assumptions continues to govern. Although the limits of (no-)arbitrage are well discussed in literature, e.g. compare Shleifer and Summers (1990) and Ritter (2003), the innovation in risk modeling is taking place - if at all - very slowly. Besides the assumption of no-arbitrage, which has its most popular application in the formula of Black and Scholes (1973), there are still hypotheses in the background of these models, which in the meantime can hardly be accepted from an empirical point of view. Still, internal models of large banks are mainly driven by the assumption that the logarithmic risk factors of their financial instruments more or less follow a random walk. This kind of modeling is rooted in Fama (1970)'s efficient-market hypothesis proposing that at least all public available information is already captured by current prices. Moreover, nothing else remains for tomorrow's prices but to assume that the change of the underlying information is well enough assessed by a random disturbance. Implicitly, this puts market prices close to a valuation which is mainly based on changes in the fundamentals. The problem with this perspective is, as e.g. Lux (1998) points out, 
that observable financial market phenomena often do not coincide with the process of new information. For instance, turbulent market periods, producing fat-tails in the distribution of returns often cannot be explained sufficiently by a change in the fundamentals according to the upcoming news about a company.

Another cornerstone of present risk modeling is the concept of rational expectations, which directly approves a centered stochastic error term sufficiently describing the difference between the representative agent's ${ }^{1}$ expectation and the current equilibrium price. The problem here is that the assumption of a centered disturbance or of complete information or of perfect capital markets in general is just too simple. Davidson (1982) rejected the rational expectation hypothesis on the grounds of non-ergodicity ${ }^{2}$ and non-stationarity which often can be found in economic time series. Although modern risk management models do not directly fail to consider these properties ${ }^{3}$ of a stochastic process, his analysis may be right in the sense that, based on the rational expectation hypothesis, there is too much simplicity left. This, in particular, prevents these models from capturing the systemic risk of turbulent markets.

Colander et al. (2009) provide an excellent analysis about the 'the financial crisis and the systemic failure of academic economics' which in their view was caused by 'a misallocation of research efforts in economics.' The same seems to be true for the special field of risk modeling although alternatives for financial market modeling have been around for some time, see DeLong et al. (1990), Campbell and Kyle (1993) and Arthur et al. (1996) among others. Nevertheless, their analysis, in which market participants partly follow rules of thumb or market psychology, was widely ignored in risk management models although staff members with trading experience could have known better. Or in the words of Colander et al. (2009, page 1$)$ :

We trace the deeper roots of this failure to the profession's insistence on constructing models that, by design, disregard the key elements driving outcomes in real-world markets. The economics profession has failed in communicating

\footnotetext{
${ }^{1}$ At this point one could already start the discussion why it is not feasible to have more than one type of agent in a model. In the literature, e.g. Kirman (1992), there are good reasons against a unique representative agent. Thus it is plurality that lies at the heart of models with heterogeneous agents. The presented one deals with three different type of agent for each market.

${ }^{2}$ Note that the stochastic processes in the presented agent-based model are all time-in-homogeneous.

${ }^{3}$ Of course the Geometric Brownian Motion underlying the Black-Scholes formula contains a drift.
} 
the limitations, weaknesses, and even dangers of its preferred models to the public.

The academic financial literature identifies three basic directions addressing the abovequoted weaknesses so that they are able to reproduce the so-called market anomalies ${ }^{4}$ :

- the econometric approach, in particular GARCH/FIGARCH models, see among others Bollerslev et al. (1994) and Baillie et al. (1996)

- the geometric approach, in particular FRACTAL models, see among others Mandelbrot and van Ness (1968) and Mandelbrot et al. (1997)

- the behavioral approach, in particular Agent-based Computational Economic models, see among others Lux (1998) and Lux and Marchesi (2000)

At least the latter two items are rarely used for risk management although they provide some useful intuition about the main factors producing the anomalies ${ }^{5}$, whereas the first one, while 'capturing the time series properties of financial data by some stochastic model, does not explain the underlying regularities', see Lux (1998, page 144). For simplicity reasons the presented paper concentrates on the agent-based approach but the proposal could, in general, encompass all the approaches within the regulatory framework so that 'model uncertainty ... (can be) taken into account by applying more than a single model', see Colander et al. (2009, page 6). At least we will be able to calculate the maximum value-at-risk (VaR) out of the current IMM and the proposed agent-based model.

The inability of most of the present risk models to reproduce the so-called anomalies ${ }^{6}$ also plays an important role ${ }^{7}$ in the debate about whether steps taken towards a better financial market regulation up to now are sufficient. In their penetrating analysis Horn et al. (2009) reviewed the most important proposals for improving financial regulation: (1) All risks of financial institutes should be captured by their balance sheets (and maybe

\footnotetext{
${ }^{4}$ Especially the phenomena of excess volatility and volatility clustering - both linked to the origination of bubbles - have to be mentioned.

${ }^{5}$ A nice intuition for Mandelbrot et al. (1997)'s multifractal nature of trading hours is the notion that in turbulent market periods 'the clock is ticking faster.' The intuition provided by agent-based models will be discussed in detail later on.

${ }^{6}$ In this context it might be more appropriate to speak about stylized facts, also see Pagan (1996).

${ }^{7}$ There might be exemptions with special Lévy alpha-stable distributions or jump processes but here again everything is true what has been said so far about GARCH models.
} 
even more importantly by their risk management ${ }^{8}$ ) and all of them should be secured by regulatory capital. (2) In general there should be a certain minimum regulatory capital to ensure against the risk of crises. Regulatory capital required by the regulatory authority should be designed in a countercyclical manner. (3) Risk management models of the financial institutes should also cover the systemic risk. (4) The biggest part of trading on derivatives markets should take place under a better control of banks and exchanges. All these proposals also fit to an examination by Alexander et al. (2012) who find evidence that 'the Basel framework allows banks to take substantive tail risk in their trading books without a capital requirement penalty.'

On the one hand, the new regulatory framework by the Basel Committee on Banking Supervision (2010), Basel III, tries to draw lessons from the financial crisis by changing the assignment of what is accepted as regulatory capital ${ }^{9}$. On the other hand, it can be criticized that to little is done to improve the concrete risk management models linked to the first pillar of Basel II. Systemic risk should be accounted for at a point, where risks are really quantified, namely in the VaR approaches for market, credit and operational risk instead of shifting it towards the more abstract rules of the second pillar. This is the starting point for the paper at hand and it will be shown that many of the proposals for improving financial regulation, as summarized above from Horn et al. (2009), are reflected in the results of the agent-based simulations.

This paper contributes to the literature by accommodating the idea of agent-based computation to the existing regulatory framework. For this purpose of risk calculation a modified version of the model Lux and Marchesi (2000)-model is developed. Extensions are two-sided. On the one hand, measures are taken to reduce the influence of calibration and to put the agent-based simulations closer to observable data. This enables the model to work within the Basel framework, where the last 250 realizations of the risk factors shall be taken into account. On the other hand, the model is extended to include the derivatives market, which shows that the approach is not limited to the stock market (or even to assess market risk ${ }^{10}$ ). Furthermore, this extension reveals a key ratio of the derivatives market which in the future, if monitored by national controlling authorities, may lower the

\footnotetext{
${ }^{8}$ There is an ongoing discussion about the different choices in the (international) accounting standards and the strict date reference of the balance sheet, which both weakens the ability to pose risks correctly.

${ }^{9}$ In particular higher core capital quota are required and countercyclical buffers are created.

${ }^{10}$ For example, it is not always clear whether credit derivatives belong to the class of credit or market risks generating instruments.
} 
influence of speculative derivatives trading. The remainder of this paper is structured as follows. Section 2 briefly discusses stylized facts observable on financial markets. Section 3 reviews a typical risk calculation according to the IMM - both for stock and derivatives markets - and presents the simulation results. Section 4 develops an agent-based model for market risk calculation - again for both markets - and provides the results. Section 5 deduces policy implications from the previous results. Section 6 finally concludes.

\section{Anomalies or Stylized Facts ?}

Figure 1 presents the stock price returns of two different samples - one before and one during the recent financial crisis. Both are part of the presented risk calculation, where for our findings the exact temporal delimitation is of secondary importance. What immediately attracts the attention in the sub-figure on the left are the peaks of the new economy and of last crisis' bubble ${ }^{11}$. Illustrated on the right we find periods, where weak market-efficiency could hold (upper right) and where not (lower right). Additionally, excess volatility is only striking at the beginning and at the end ${ }^{12}$ of the lower right sample interrupted by a relatively calm market period. Summarizing one can speak about volatility clustering.

It is remarkable how matter-of-factly much of the literature uses the terms anomaly or curiosa to describe the above-mentioned empirical facts - just as if market-efficiency and no-arbitrage phases were the only natural state of financial markets. In contrast, Pagan (1996) in his seminal contribution paints a complete picture, where (for univariate financial series) he examines the questions of (1) stationarity, (2) independent distributions over time (which is linked to non-linear modeling and volatility cluster), (3) the existence of moments and of (4) normally distributed returns (which both are linked to excess volatility). The permanent change between calm and turbulent market periods also fits the analysis of Chen et al. (2001, page 1) who find that 'explicit tests for non-linearity and dependence also give very unstable results in that both acceptance and strong rejection of IIDness can be found in different realizations.'

\footnotetext{
${ }^{11}$ Of course both bubbles differ in what was cause and what effect in each case. Nevertheless, in the light of their absolute level they seem to be comparable to each other and, although the paper at hand concentrates on the financial crisis, we want to mention the new economy bubble to emphasize the fact that bubbles are recurring phenomena.

${ }^{12}$ Lehman Brothers declared bankruptcy in September 2008.
} 

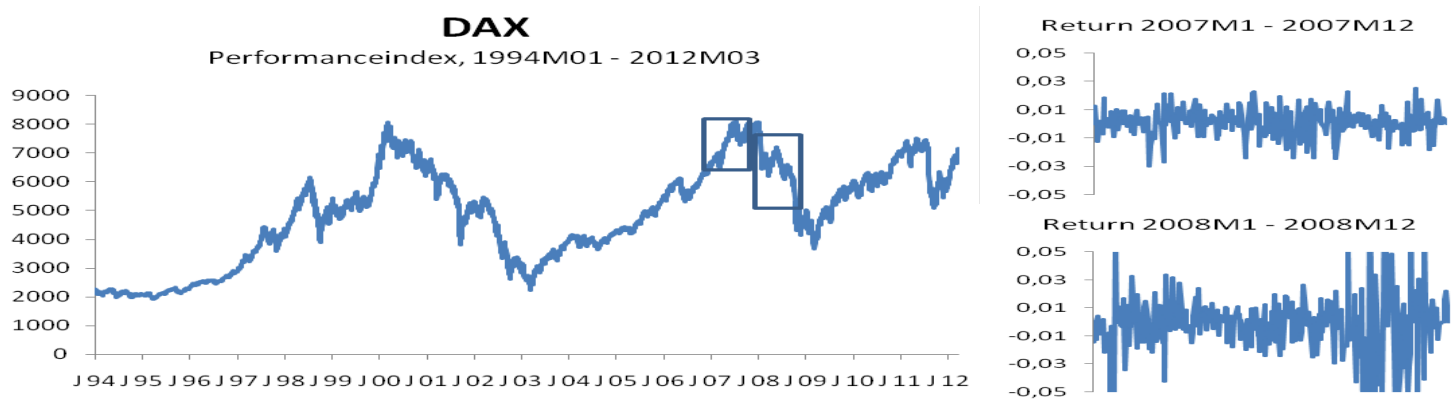

Figure 1: Stock prices and stock price returns for different samples reflecting the phenomena of excess volatility and volatility clustering - both often linked to bubbles.

Finally Lakonishok et al. (2007) ascertain that at least for the less sophisticated option traders a special behavior can be observed in bubble times. All this leads to one conclusion: It is time for the so-called anomalies to enter the world of risk management models.

\section{The Internal Model Method (IMM)}

\subsection{Stock Market}

\subsubsection{Model}

The models introduced by Black and Scholes (1973) as well as Merton (1973) assume perfect and complete capital markets. In particular, this includes homogeneous expectations and rational behavior, no transaction costs ${ }^{13}$, no short-selling constraints ${ }^{14}$ and consequently no arbitrage. Moreover the underlying asset is assumed to follow the Geometric Brownian Motion, i.e.

$$
d S(t)=\tilde{\mu} S(t) d t+\sigma S(t) d W(t), \quad d W(t) \sim N(0, d t) .
$$

By Ito's lemma we have

$$
\ln (S(t))=\ln \left(S_{0}\right)+\mu t+\sigma \sqrt{t} \epsilon, \quad t>0, \quad \tilde{\mu}=\mu+\frac{\sigma^{2}}{2} .
$$

\footnotetext{
${ }^{13}$ The agent-based approach (ABA) neither considers transaction costs directly. But one of the most discussed implications of existing transaction costs in literature is that markets are no longer arbitrage-free. And this is certainly considered with the ABA.

${ }^{14}$ In the aftermath of the financial and the European sovereign-debt crisis several nations at least partly banned short selling in their financial markets.
} 


\subsubsection{Risk Factors and Simulation Results}

\section{Simulation before the Crisis for stock A1EWWW}
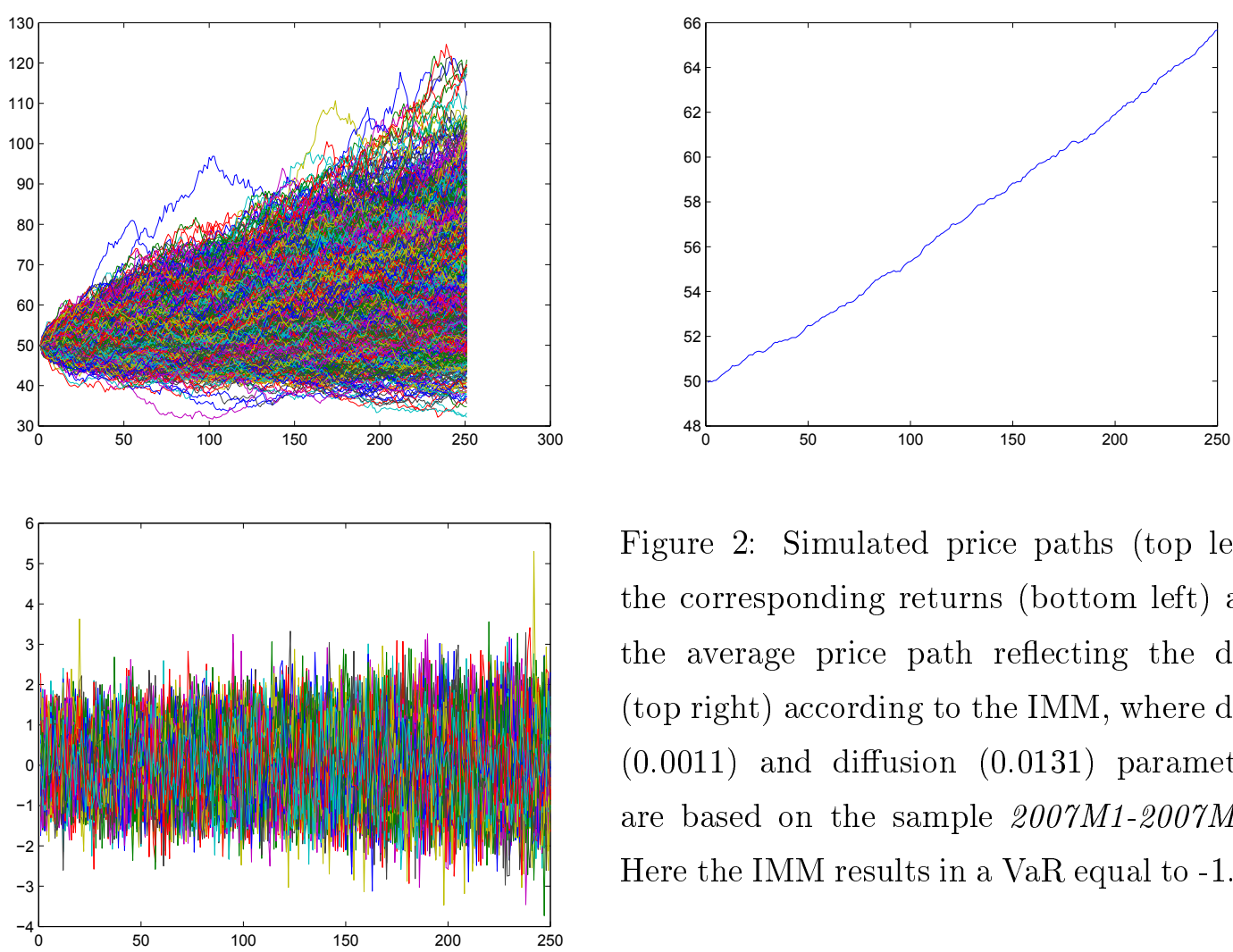

Figure 2: Simulated price paths (top left), the corresponding returns (bottom left) and the average price path reflecting the drift (top right) according to the IMM, where drift (0.0011) and diffusion (0.0131) parameters are based on the sample 2007M1-2007M12. Here the IMM results in a VaR equal to -1.70 .

In equations (1) and (2) $\tilde{\mu}$ denotes the drift parameter, $\epsilon$ a standard normal random variable, $\mu$ the average of the empirical returns and $\sigma$ the diffusion parameter or volatility. The latter two are taken from the observable market prices of the last 250 trading days. The only risk factor here is the stock itself. Its uncertainty is captured by the Wiener process $W$. For each risk calculation in this paper 50000 simulations are taken into account. Here this means that 200 price paths are produced, where one path lasts for one trading year (250 trading days) according to the Basel framework. Then the value-at-risk (VaR) can be calculated

$$
\hat{E}\left(V a R_{0.99}^{i}\right)=\frac{1}{200} \sum_{i=1}^{200}\left\lceil q_{0.01}^{i}\right\rceil\left(d S_{t}\right),
$$




\section{Simulation in the Crisis for stock A1EWWW}
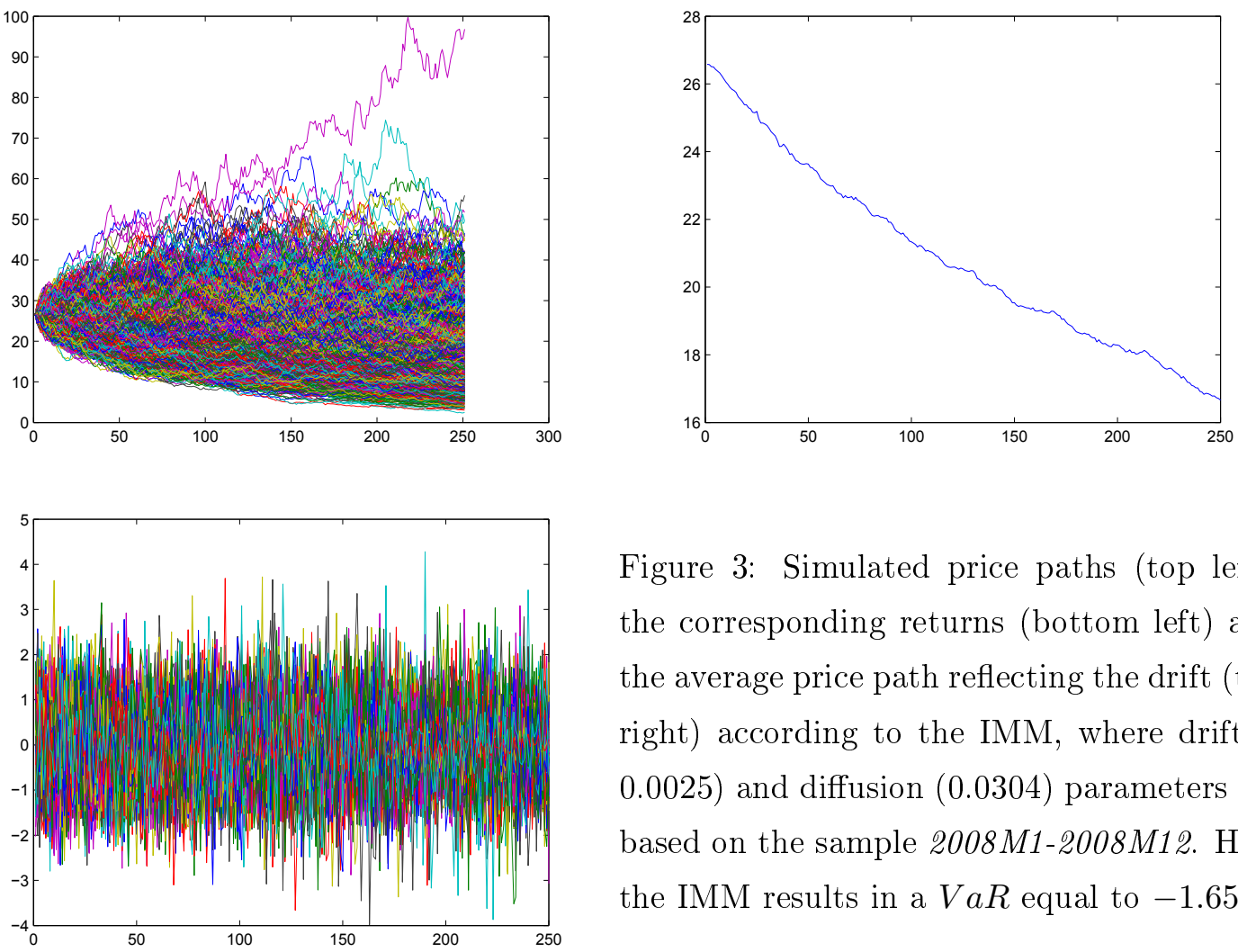

Figure 3: Simulated price paths (top left), the corresponding returns (bottom left) and the average price path reflecting the drift (top right) according to the IMM, where drift ($0.0025)$ and diffusion (0.0304) parameters are based on the sample 2008M1-2008M12. Here the IMM results in a $V a R$ equal to -1.65 .

where $q_{0.01}^{i}\left(d S_{t}\right)$ stands for the $1 \%$ quantile of the stock price differences of the $i$-th path so that $99 \%$ out of all daily losses will not exceed the VaR.

For the presented figures an arbitrary stock in the German stock index DAX was chosen 15. Figure 2 illustrates the results for a point in time before the last crisis had started and figure 3 for a point in time after the last crisis had started. The average price paths for the different points in time reflect bearish and bullish markets. At first glance the change of the VaR from -1.70 (before the crisis) to -1.65 (during the crisis) does not look exceptionally pro-cyclical. However, when considering the base level (initial prices), the VaR before the crisis comparatively seems to be too low. The reason is that the VaR is defined as the quantile of the absolute, not of the relative price changes.

\footnotetext{
${ }^{15}$ MATLAB code for both the IMM and the ABA is available on request so that risk calculation for all the stocks in the index can be executed. Section 5 contains the VaR results for two more assets.
} 


\subsection{Derivatives Market}

\subsubsection{Model and Risk Factors}

The models by Black and Scholes (1973) as well as Merton (1973) deliver (European) call and put prices. In the case of call options and for $S=S(t)>0,0 \leq t<T$ we have

$$
\begin{aligned}
C(S, t) & =S \Phi\left(d_{1}\right)-K \exp (-r(T-t)) \Phi\left(d_{2}\right) \\
C(0, t) & =0, \quad C(S, t) \sim S \text { for } S \rightarrow \infty, \quad C(S, T)=(S-K)^{+} \\
d_{1} & =\frac{\ln (S / K)+\left(r+\sigma^{2} / 2\right)(T-t)}{\sigma \sqrt{T-t}}, \quad d_{2}=d_{1}-\sigma \sqrt{T-t},
\end{aligned}
$$

where $\Phi$ stands for the normal cumulative density function. The underlying assumptions (and, according to the introduction, weaknesses) are the same as in the previous section. In this paper we only deal with call options ${ }^{16}$ but the basic ideas could also be applied to other derivatives - including interest and credit derivatives for which realizations of the risk factors are observable on a market. Hence, on a large scale the call options can be taken as representatives of derivatives market in general.

W.l.o.g. we choose the above mentioned stock as the underlying and an arbitrary strike price $K$ at the money ${ }^{17}$. A view to equation (4) reveals the risk factors, which are the stock $S$ (generated by the Wiener process), the interest rate $r$ and the volatility $\sigma$. To pose interest rate risk and volatility risk we refer to historical values. 18 In practice the acceptance of different computation methods depends on the judgment of the national regulatory authorities - in Germany BAFIN and Deutsche Bundesbank - but the procedure here can be viewed as a widely-used one. This time the decline in value-at-risk from -2.33 (before the crisis) to -1.04 (during the crisis) can be described as almost counter-cyclical. Nevertheless, also in this case it is not possible to find the anomalies ${ }^{19}$ mentioned in the introduction. Therefore the results are too smooth.

\footnotetext{
${ }^{16}$ Models can be extended to include dividend payments.

${ }^{17}$ Note that the small distance between initial and strike price is the same for both the IMM and ABA.

${ }^{18}$ Interest rates are taken from the one-month EURIBOR and the volatility is conservatively approximated by the one-percent quantile of the VDAX NEW implicit volatility index which is also linked to an one-month maturity.

${ }^{19}$ Sometimes it is argued that there are less knocking outs observable on option than on stock markets. On the one hand this adjoins a self-fulfilling prophecy if anybody is exclusively using Black-Scholes formula for his trading decision. On the other hand this leads to the fact that risk management models do not simulate the feedback effect between the markets. Compare section 5.2.
} 


\subsubsection{Simulation Results}

Simulation before and the Crisis for a call on A1EWWW
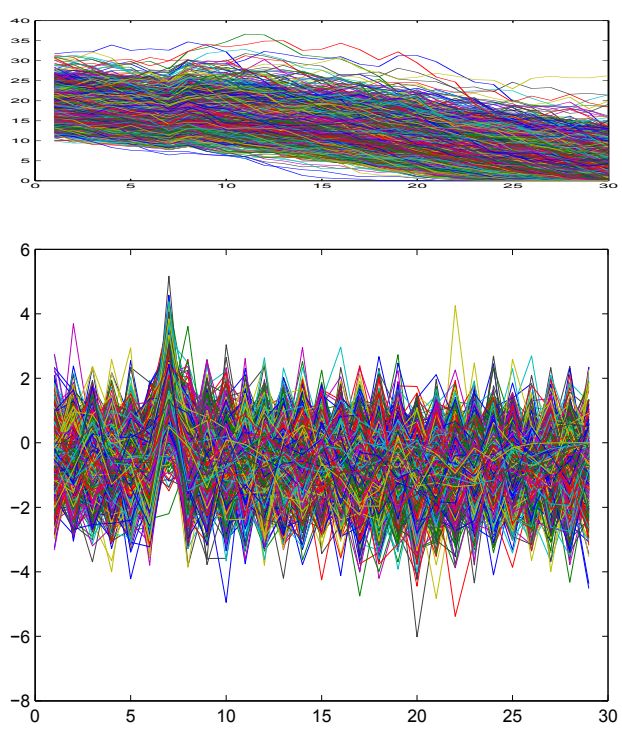

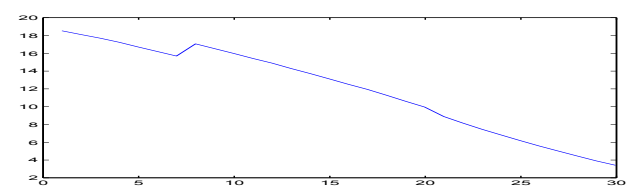

Figure 4: Simulated option price paths (top left), the corresponding returns (bottom left) and the average price path reflecting the time value (top right). The IMM uses Black-Scholes formula, where volatility $\epsilon$ $[0.134,0.314]$, interest $\in[0.0417,0.0495]$ and stock prices are based on the sample 2007M12007M12. This results in a $V a R=-2.33$.

Simulation in the Crisis for a call on A1EWWW
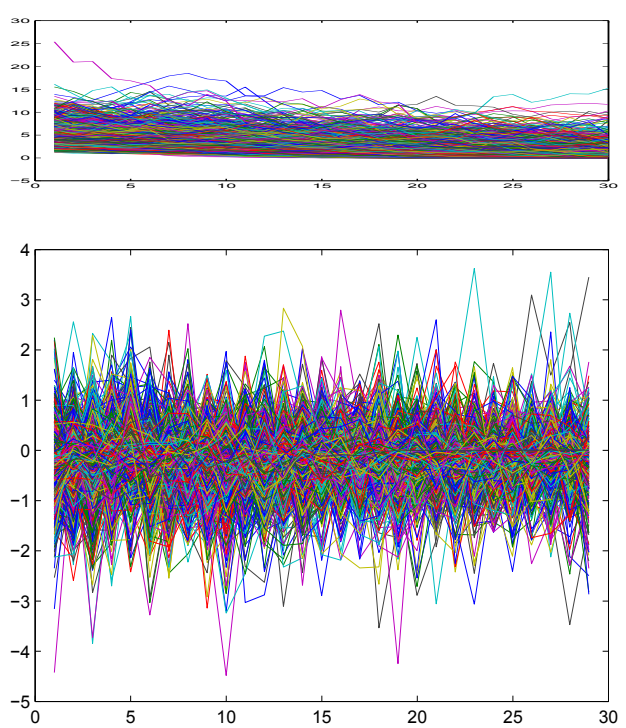

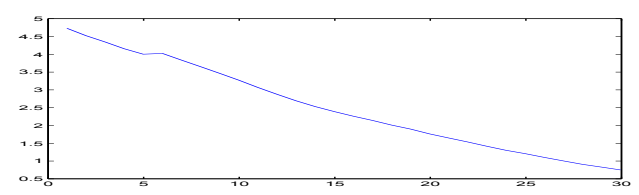

Figure 5: Simulated option price paths (top left), the corresponding returns (bottom left) and the average price path reflecting the time value (top right). The IMM uses Black-Scholes formula, where volatility $\in$ $[0.173,0.832]$, interest $\in[0.0260,0.0361]$ and stock prices are based on the sample 2008M12008M12. This results in a $V a R=-1.04$. 


\section{The Agent-Based Approach (ABA)}

\subsection{Stock Market}

\subsubsection{Agents and their Dynamics}

What lies at the heart of the model by Lux (1998), Lux and Marchesi (2000) are three different classes ${ }^{20}$ of agents: (1) optimistic noise traders $(+)$, who want to buy the stock out of a motivation that has to be clarified hereinafter. (2) pessimistic noise traders (-), who want to sell the stock out of a motivation just opposite to the previous one. (3) fundamental traders (f), who want to make money by arbitrage between the market price and a fundamental price which also has to be clarified hereinafter. At each point in trading time the agents interact and decide whether to stay or to change the class.

For the purpose of risk calculation according to the Basel framework the design by Lux and Marchesi (2000) has been remodeled in several ways. That is why there is no alternative than to review the model in principle. As a first stage the agents' dynamics are described. These dynamics are driven by rules of thumb or behavioral rules, which simultaneously represent the main risk factors of the model. Subordinated risk factors cause the fluctuations of the fundamental price. The transition process describing the agents' dynamics is assumed to follow a first order inhomogeneous Markov chain, which has a uniform starting distribution and whose transition matrix looks like

$$
\left(\begin{array}{ccc}
1-\pi_{+-}^{t}-\pi_{+f}^{t} & \pi_{+-}^{t} & \pi_{+f}^{t} \\
\pi_{-+}^{t} & 1-\pi_{-+}^{t}-\pi_{-f}^{t} & \pi_{-f}^{t} \\
\pi_{f+}^{t} & \pi_{f-}^{t} & 1-\pi_{f+}^{t}-\pi_{f-}^{t}
\end{array}\right)
$$

We will discuss two of the transition probabilities in detail and refer to Lux and Marchesi (2000) for the rest. The first one is the transition within the noise traders (n) - here from the optimist to the pessimist:

$$
\pi_{+-}^{t}=\min (v_{1} \underbrace{\frac{n_{t}^{n}}{N}}_{(1)} \exp \left(-(a_{1} \underbrace{\frac{n_{t}^{+}-n_{t}^{-}}{n_{t}^{n}}}_{(2)}+a_{2} \underbrace{\frac{p^{\prime}(t)}{p(t)}}_{(3)})\right), 1) .
$$

\footnotetext{
${ }^{20}$ We explicitly refer to class in terms of set theory.
} 
In equation (6) three different influencing factors are emphasized: (1) denotes the probability of meeting another noise trader. Thereby, the denominator $N$ stands for the constant number of market participants in the model. (2) denotes the impact of herding behavior. In the case of a lower number of optimists this will reinforce the change to the pessimists' class. (3) denotes the impact of extrapolating the actual trend. Here a positive price derivative will damp the change to the pessimists' class. $a_{1}=1-a_{2}$ controls the weighting between majority opinion and actual trend. We choose a uniform weighting due to the lack of information that any other weighting would be more appropriate. $v_{1}=1-v_{2}$ sets the frequency of revaluation among traders meeting each other - here among noise traders. $v_{2}$ is used for the case that a noise trader meets a fundamentalist and vice versa. We choose slightly different values $\left(v_{1}=0.6, v_{2}=0.4\right)$ because we assume the interaction process in the first case to be faster than in the second. The reason therefore is that noise and fundamental traders in principle believe in different investment strategies ${ }^{21}$ and it takes some time to get to know the other side before one can opt for a change.

The second transition probability described here is responsible for the change from the pessimistic agents' class to the fundamental one:

$$
\pi_{-f}^{t}=\min (v_{2} \underbrace{\frac{n_{t}^{f}}{N}}_{(1)} \exp \left(-a_{3}^{t, e}(\underbrace{R-\frac{d_{t}+\frac{1}{v_{2}} p^{\prime}(t)}{p(t)}}_{(2)}-\underbrace{\left.\left|\frac{p_{t}^{f}-p(t)}{p(t)\left(1+\hat{r}_{M}\right)}\right|\right)}_{(3)}), 1\right) .
$$

Again the dynamics are restricted to three factors: (1) denotes the probability of meeting a fundamentalist. (2) denotes the return of a pessimist, which itself consists of the return of an alternative investment $(\mathrm{R})$ less the return of the stock ${ }^{22}$. The pessimist extrapolates the actual trend, which - if negative - encourages him to sell. (3) denotes the return of a fundamentalist and corresponds to the discounted profit of arbitrage between the fundamental price $p^{f}$ and the market price $p$. Altogether a change is motivated by the comparison of the returns, where in addition $a_{3}^{t, e}$ measures the traders' reaction on the return differences. When looking for dynamics of this reaction, adaptive expectations tell us

$$
a_{3}^{t, e}=a_{3}^{t-1, e}+\lambda\left(a_{3}^{t-1}-a_{3}^{t-1, e}\right), a_{3}^{1, e} \doteq 1,
$$

\footnotetext{
${ }^{21}$ Fundamental traders basically believe in efficient-market hypothesis. Noise traders for instance can be thought of being chartists.

${ }^{22} \mathrm{~d}$ stands for the dividend.
} 
where we treat the second part as a forecast error with $\epsilon_{t}^{a_{3}} \sim N\left(0,(U[0,0.01])^{2}\right)$. The small standard deviation ${ }^{23}$ ensures that the reaction on return differences is kept in a realistic range, e.g. ]0,2] can either mean that the difference in returns almost does not matter or that its importance is doubled. Modeling $a_{3}^{t, e}$ in the way mentioned above opens space for interpretation instead of arbitrarily setting the parameter unequal to 1 , as it is partly done in Lux and Marchesi (2000). For instance let us consider the change from a noise trader to a fundamentalist: Firstly if $a_{3}^{t, e}>1$, then the change is reinforced. This might reflect adaptive learning. Noise traders might be keen on (neoclassical) finance (literature). Secondly if $a_{3}^{t, e}<1$, the change is weakened. Noise traders might be overconfident with respect to their investment strategy and remain unchanged, e.g. see Alicke and Govorun (2005).

So far, we covered the agents' dynamics. Missing parts are the fundamental price and the question of how the agents' dynamics are transferred into a market price. But before dealing with these issues in detail it is worth to highlight the trading time underlying the price process. In fact the model uses discrete time linked to intraday trading. Each and every twelve minutes ${ }^{24}$ trading takes place, the agents decide to which class they want to belong and stock prices are updated.

\subsubsection{Fundamental Price Process}

In principle the fundamental price is originated from a discounted cashflow model and in analogy to neoclassical economics the fluctuations emerge from shocks of the (infinite) dividend cashflow and the corporate growth rate. Fundamental traders use this price to recognize arbitrage opportunities. In contrast to Lux and Marchesi (2000) in this paper we utilize the Capital Asset Price Model (CAPM) and Gordon's formula to compute the fundamental price, which both can be aligned with the rational-expectation and efficientmarket hypotheses mentioned in the introduction. From the perspective of a modeler this does not mean to conceal all the empirical doubts which arose over the years with these models, but just to assume that there are market participants who really believe in them ${ }^{25}$. Precisely they believe that market prices sooner or later converge to their results. Otherwise it would not make sense to employ them for the search of arbitrage opportunities.

\footnotetext{
${ }^{23} U$ denotes here the drawing of uniformly distributed random numbers within the interval.

${ }^{24}$ We count 8 hours for a trading day. Hence an elementary time unit is equal to 0.025 trading days.

${ }^{25}$ In view of finance lessons at universities this should not be too unrealistic.
} 
Moreover these models allow for an automatized determination of the fundamental price.

When looking back to the transition probability in equation (7), the requirement to determine $R$ and $\hat{r}_{M}$ becomes obvious. While selecting a stock index as the 'market portfolio' (M) ${ }^{26}$, the CAPM computes individual $\beta$-factors and risk free rates by

$$
\hat{\beta}_{i}=\frac{\operatorname{cov}\left(\hat{r}_{M}, \hat{r}_{i}\right)}{\sigma_{M}^{2}}, \quad \hat{r}_{f}^{i}=\frac{\hat{r}_{M} \hat{\beta}_{i}-\hat{r}_{i}}{\hat{\beta}_{i}-1}, \quad i=1, \ldots, 30 .
$$

Then the average of the risk free rates is selected to stand for the return of the (risk free) alternative, i.e.

$$
R:=\frac{1}{n} \sum_{i}^{n} \hat{r}_{f}^{i}, \quad n=30 .
$$

Simultaneously the return of the market portfolio is chosen as the relevant discount rate for arbitrage activity. ${ }^{27}$ Moreover $(1-b)$ stands for the observable payout ratio per share and $d_{t}=(1-b) g_{t}$ for the dividend per share. As mentioned before we add shocks to the profits per share $(g)$ and to the core growth rate $(c g)$ of the company value ${ }^{28}$, i.e.

$$
\begin{aligned}
g_{t} & =g_{1}+\epsilon_{t}^{g} \\
c g_{t} & =c g_{1}+\epsilon_{t}^{c g} .
\end{aligned}
$$

Finally Gordon's formula, basically the infinite geometric series, delivers the fundamental price by

$$
p_{t}^{f}=\frac{g_{t}(1-b)}{R-b c g_{t}} .
$$

Campbell and Kyle (1993) call their fundamental traders 'smart money', since they definitely use more sophisticated models than the noise traders. But in general this does not guarantee them better returns. Despite their supposed superiority there is much evidence that in periods with strong price gains or losses they give up their position to follow the trend and become noise traders, see Shleifer and Summers (1990).

\subsubsection{Market Price Process}

So far, the number of agents in each trading class and for each point in time is calculated. Now the question arises what conclusions to the market price can be drawn from this. Lux

\footnotetext{
${ }^{26}$ As mentioned before data for all stocks linked to the DAX is loaded for the agent-based risk calculation.

${ }^{27}$ Because of the well-known risk that the trader fails to make profit by arbitrage this rate should be higher than the risk free rate.

${ }^{28} \sigma^{g}$ and $\sigma^{c g}$ are intuitively set to 1 cent respectively to 100 basis points since we do not know any better.
} 
and Marchesi (2000) define the (expected) excess demand ((E)ED) of noise traders by

$$
E E D_{t}^{n}=\left(n_{t}^{+}-n_{t}^{-}\right) \operatorname{vol}_{m o d}
$$

Thus, in the case of a majority of optimists versus pessimists, the EED will be positive, otherwise negative. Simultaneously, the excess demand corresponds to the difference between the noise trader groups weighted by an average trading volume per transaction. The expected excess demand generated by fundamentalists is then defined by

$$
E E D_{t}^{f}=\frac{p_{t}^{f}-p(t)}{p(t)} n_{t}^{f} \operatorname{vol}_{m o d}
$$

Here a higher fundamental than observable price is an incentive for the 'smart money' trader to buy, otherwise to sell. This incentive is divided by the current market price to form a fraction of the fundamentalists' class as a whole. ${ }^{29}$ This subset weighted again by the average trading volume per transaction corresponds to their expected excess demand.

The trading volume plays an important role in keeping simulated prices in a realistic range. ${ }^{30}$ Instead of direct calibration like Lux and Marchesi (2000) we try to derive the trading volume of the model $\left(v_{\text {ol }}\right.$ mod $)$ from observable XETRA data $\left(v_{o l}{ }_{\text {obs }}\right){ }^{31}$ Therefore we employ the following OLS regression

$$
\operatorname{vol}_{\text {mod }}=\beta \operatorname{cap}\left(\operatorname{vol}_{o b s}, N, p_{1}\right)+u, \quad \text { where } c a p:=\left(\frac{1}{v_{\text {obl }}}\right)^{\left(\frac{1}{p(1)}\right)} N^{\left(\frac{1}{v_{o l o b s}}\right)} .
$$

Note that - besides the observable trading volume - the regressor cap also considers the current market price and number of market participants in the model. Reasons for this are as follows: The higher the real-world average trading volume (per transaction) the more difficult it is for the model to reproduce this. The higher the real-world price level the lower tends the real-world average trading volume to be. The higher the number of participants in the model the easier it is for the model to reproduce a higher trading volume. Of course, it is difficult to find an ultimate functional form for the interdependences mentioned above, but the presented one at least delivers an acceptable fit, see figure 6 .

\footnotetext{
${ }^{29} \mathrm{~A}$ possible explanation is that the rest of the fundamental traders could clear their transactions or is not willing to trade at all.

${ }^{30}$ On the one hand future risk management models should consider the systemic risk of bubbles. On the other hand risk management practice requires models which do not produce astronomical prices. Note that figure 10 illustrates the extremest outcome of our model. If one still considers this as unrealistic, the results could be treated as outliers and replaced by the next simulation.

${ }^{31}$ This data is loaded from www.ariva.de.
} 


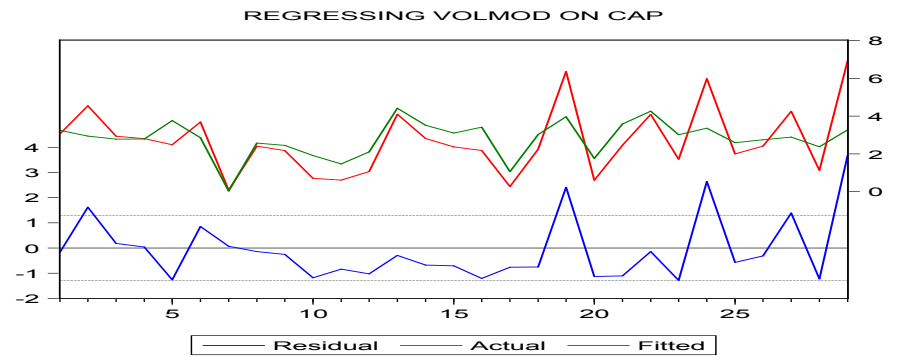

Figure 6: Actual and fitted model trading volumes (per transaction) for the DAX portfolio. Actual values are produced by the rule that existing bubbles should be kept in a realistic range, i.e. $p(t) \in[0,2 p(1)] \forall t$. The adjusted $R^{2}$ is equal to 0.46 .

The total expected excess demand for a certain point in time is then given by

$$
E E D_{t}=E E D_{t}^{n}+E E D_{t}^{f}
$$

It will be readily apparent, why we in contrast to Lux (1998) explicitly refer to an expectation. Concerning this matter, it is assumed that the stock price follows an inhomogeneous Poisson process, i.e. the number of jumps between $t$ and $t+1$ is Poisson distributed:

$$
P\left(\#\{\text { jumps }\}_{t}=k\right)=\exp \left(-|E E D|_{t}\right) \frac{|E E D|_{t}^{k}}{k !}, \quad k \in N_{0}
$$

where the intensity is equal to the total expected excess demand and each jump is linked to a price increase or decrease of 1 cent. In fact this forms a relatively elegant way to transfer the agents' dynamics into price dynamics. Instead of the presented Poisson process Lux and Marchesi (2000) use the following probabilities for a binary decision problem:

$$
\pi_{\uparrow p}=\max (0, \beta(E D+\mu)), \quad \pi_{\downarrow p}=-\min (0, \beta(E D+\mu)) .
$$

The main reason, why to change this, was not the additional stochastic term $\mu$ (money maker), but the additional calibration that would be necessary for $\beta$. Instead, by just determining the expectation, but not the realization of $\#\{j u m p s\}$ the Poisson process allows to cover different grades of optimism and pessimism. In the next section we turn to the simulations generated by the presented methodology. What we will find there are reasonable values-at-risk which should be used to supplement the regulatory framework. 


\subsubsection{Risk Factors and Simulation Results}

\section{Simulation before the Crisis for stock A1EWWW}
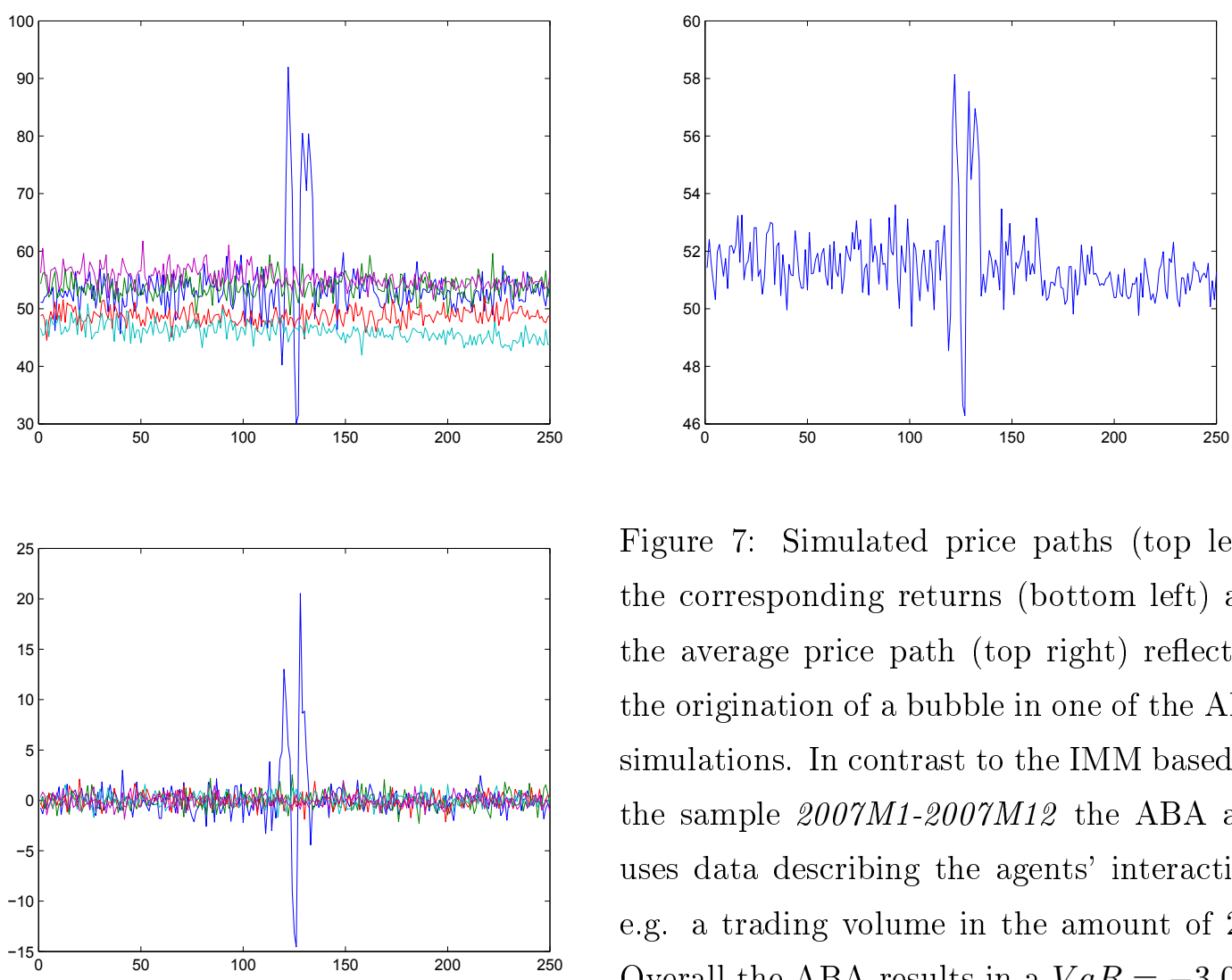

Figure 7: Simulated price paths (top left), the corresponding returns (bottom left) and the average price path (top right) reflecting the origination of a bubble in one of the ABA simulations. In contrast to the IMM based on the sample 2007M1-2007M12 the ABA also uses data describing the agents' interaction, e.g. a trading volume in the amount of 2.9 . Overall the ABA results in a $V a R=-3.04$.

First, this section repeats the data loaded to calculate the agent-based values-at-risk of the stock market. Beside the stock prices from the last 250 trading days, which were also used in the case of the IMM, these are dividend payout ratios, profits per share and trading volumes. Again we run 50000 simulations which now equals 5 times 10000 elementary time units. Because of allowing for intraday trading these elementary time units just correspond to one trading year. Thus, while the number of simulations is the same as in the case of the IMM, the agent-based value-at-risk is based on a much lower number of price paths ${ }^{32}$. Hence the agent-based VaR is calculated by $\widehat{V a R}=\frac{1}{5} \sum_{i=1}^{5}\left\lceil q_{0.01}^{i}\right\rceil\left(d S_{t}\right)$.

\footnotetext{
${ }^{32}$ Certainly, this leaves room for future extensions. The reason why we decided for the same number of simulations instead of price paths is just the visibly longer running time in the second case.
} 


\section{Simulation before the Crisis for stock A1EWWW}
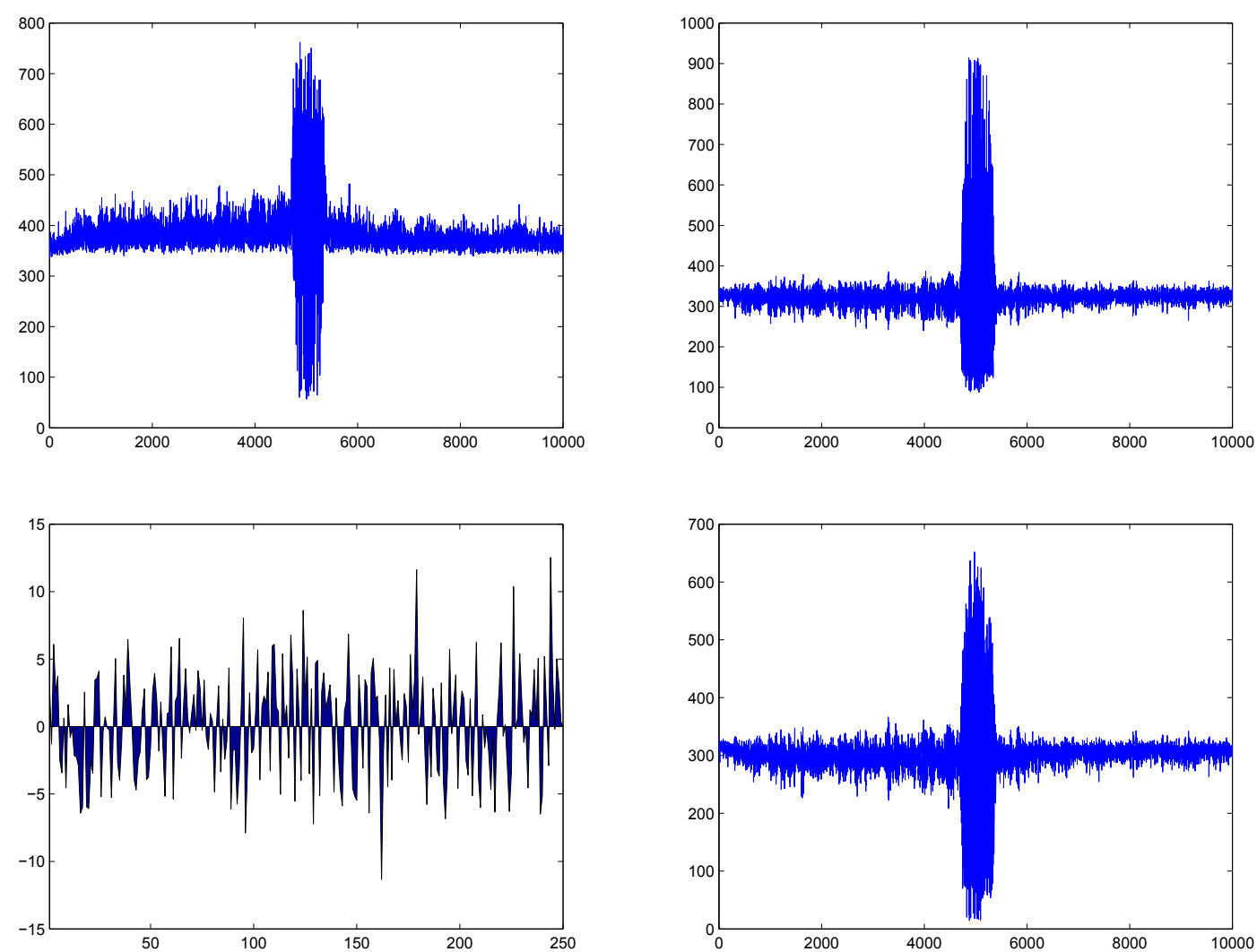

Figure 8: Agents' dynamics for one of the simulated price paths, namely for the one that embodies the origination of a bubble. By averaging, parts of the corresponding systemic risk enter into the agent-based $V a R$. The top left figure plots the dynamics for the stock market fundamental trader, the top right for the optimistic noise trader and the bottom right for the pessimistic noise trader, while the number of all market participants equals $N=1000$. The bottom left displays the returns of the so-called fundamental price process.

Basically the VaR computation in the case of the ABA is closely related to a potential bubble or at least the phenomena of excess volatility and volatility clustering. This is fully intended, since if these phenomena can occur in real-world trading indeed, their occurrence should also be simulated. While referring to DeGrauwe et al. (1993), 


\section{Simulation in the Crisis for stock A1EWWW}
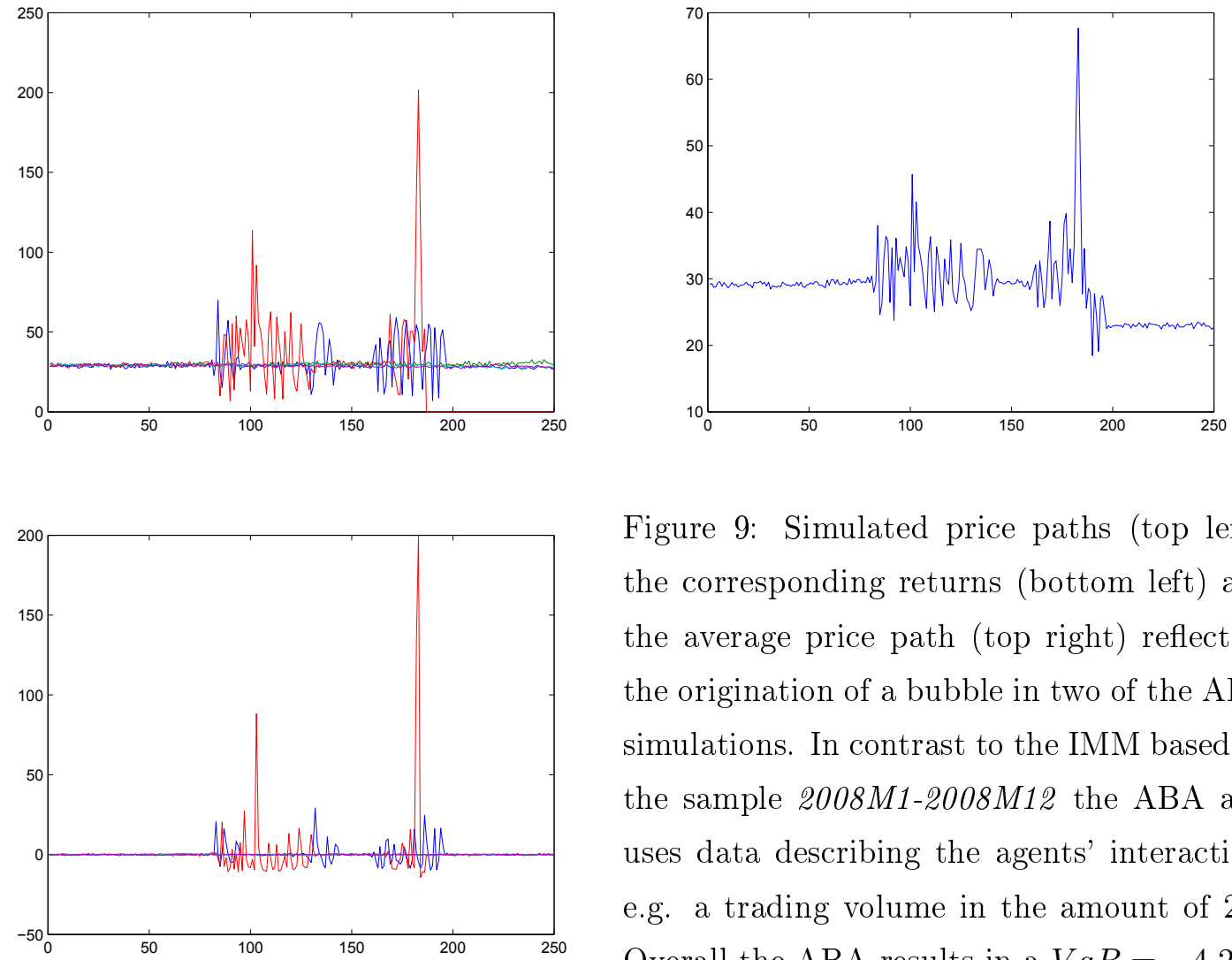

Figure 9: Simulated price paths (top left), the corresponding returns (bottom left) and the average price path (top right) reflecting the origination of a bubble in two of the ABA simulations. In contrast to the IMM based on the sample 2008M1-2008M12 the ABA also uses data describing the agents' interaction, e.g. a trading volume in the amount of 2.0. Overall the ABA results in a $V a R=-4.29$.

who were among the first to model exchange rates based on chaotic attractors, Lux (1998), page 145, explains the underlying mechanism of the agent-based financial market:

'The key mechanisms of [such] models are the following: (1) chartists' positive feedback reaction destabilizes the equilibrium in which price equals fundamental value, (2) an increasing strength of the fundamentalists' reaction upon differences between actual market price and fundamental value keeps in check the otherwise unstable oscillations.'

In other words, markets do not always tend to turbulences, but again and again. 


\section{Simulation in the Crisis for stock A1EWWW}
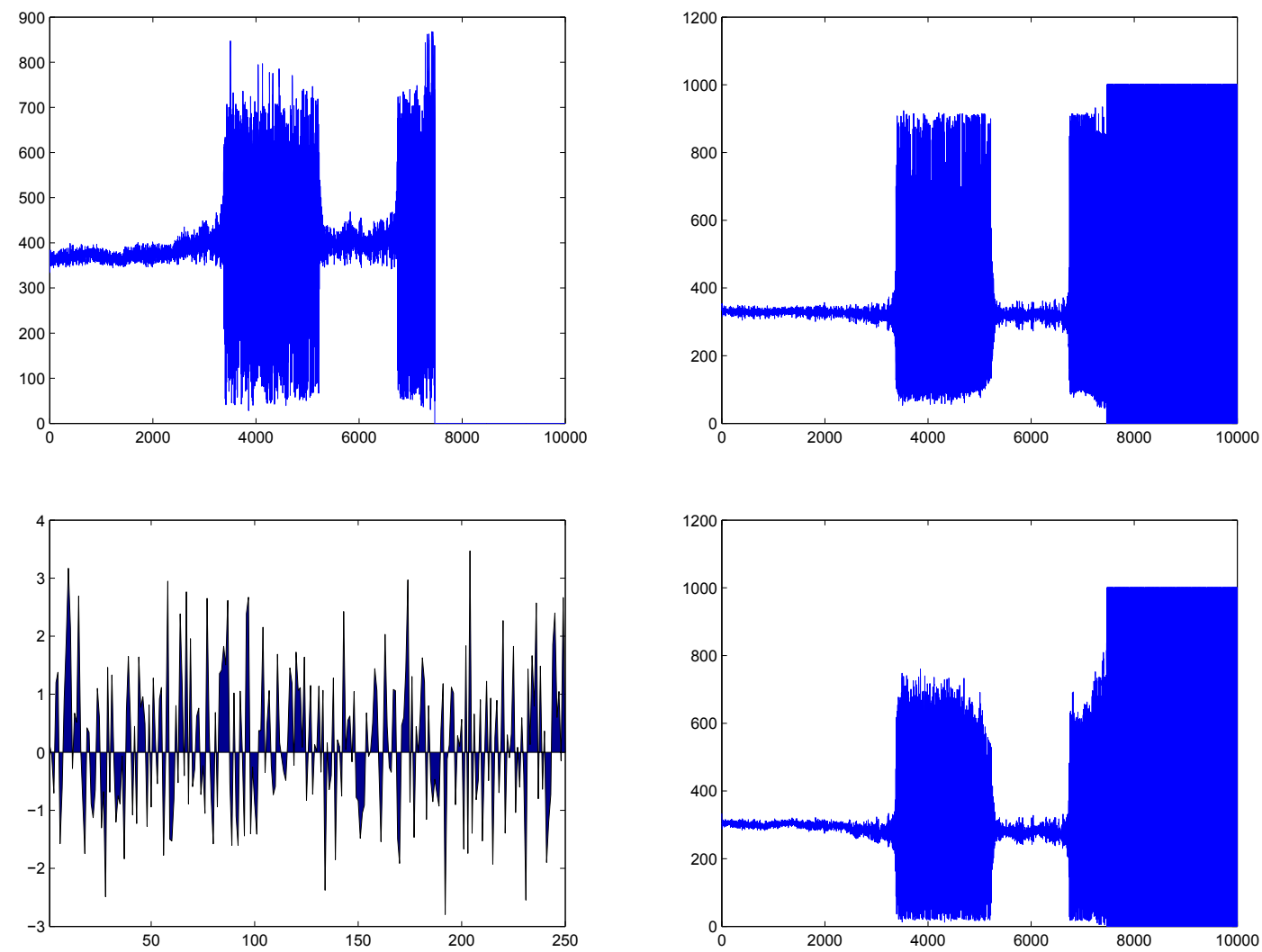

Figure 10: Agents' dynamics for one of the simulated stock price paths, namely for the one reflecting the extremest outcome of all the presented simulations with the ABA model. For the meaning of each sub-figure compare the caption of figure 8. Note that not each agentbased price path produces a bubble which truly reflects the fact that market-efficiency in general, but not automatically for a short-term sub-period is a fallacious hypothesis.

Exactly this is reflected in the results of figures 7 - 10. In the simulations for the time before the crisis one path with price anomaly can be found, in the simulations for the time during the crisis even two. As previously mentioned, the latter case illustrates extreme results compared to the outcome of all other simulations. ${ }^{33}$ Nevertheless, we do not treat this specific outcome as an outlier, because it shows that all in all the trade-off between

\footnotetext{
${ }^{33}$ One of the simulated price paths even snaps off.
} 
the consideration of anomalies and non-astronomical prices is achieved very well in the presented model. At least the average price path from the respective simulations (upper right sub-figure of figure 9) completely moves within a realistic range and still the majority of simulated price paths describes a relatively calm (or efficient) market.

The increase in VaR from -3.04 (before the crisis) to -4.29 (in the crisis) is also due to the fact that the number of price paths with anomalies increases. Thus we do not obtain a counter-cyclical development in contrast to the other two assets, for which VaR results can be looked up in table 1. ${ }^{34}$ However, VaR results are at a significantly higher level than with the IMM. In the important case of the time before the crisis the agent-based value-at-risk - if already imbedded into the regulatory framework - would have caused a closer alignment of business strategy.

\subsection{Derivatives Market}

\subsubsection{Agents and their Dynamics}

As already set out in section 3 throughout this paper derivatives markets are reduced to European call options. For the extension of the Lux (1998)-model to the derivatives market we also refer to three different types of agents: (1) derivatives long noise traders (dl), who expect to benefit from a long call position. (2) derivatives short noise traders (ds), who expect to benefit from a short call position. (3) derivatives fundamentalists, who want to make money by arbitrage. Furthermore, for the purpose of risk calculation we introduce three other variables: Let frac denote the fraction of market participants who trade derivatives alongside equities. ${ }^{35}$ Moreover let $T_{\text {call }}$ stand for the maturity of the contract (30 days). Finally a systemic hedge ratio $h$ is introduced. This indicates the fraction of derivatives contracts used for the purpose of hedging. In other words these are covered call positions. We will analyze two possible cases $h=0.25$ and $h=0.75$ and argue that this key ratio should be monitored by the regulatory authorities in the future.

On the one hand a derivatives long noise trader can be an optimist concerning the underlying asset. Hence he uses the derivative for additional speculation. On the other hand a derivatives long noise trader can be a pessimist, when it comes to the underlying.

\footnotetext{
${ }^{34}$ Note that a decline of the average trading volume per transaction in the model from 2.9 to 2.0 fits quite well to the real-world behavior from before to during the crisis.

${ }^{35}$ W.l.o.g. frac is set equal to $20 \%$. $h$ should always be related to a certain underlying.
} 
In this case he uses the derivative to hedge his position. Thus the overall result for the first type of agent is given by

$$
\#\{d l\}_{t}=\operatorname{frac}(1-h) n_{t}^{+}+\operatorname{frac} h n_{t}^{-} .
$$

This means that the number of derivatives long noise traders mainly depends on the number of optimists and pessimists in the underlying market (and thus implicitly on all rules of thumb installed there) as well as on the 'systemic hedge ratio', which here is assumed to be time-invariant.

Similarly, a derivatives short noise trader can either be a pessimist or an optimist concerning the underlying asset. In the first case he uses the call option for additional speculation and aims at the option premium. In the second he hedges his position to the extent of the option premium. Thus the overall number of derivatives short noise traders is given by:

$$
\#\{d s\}_{t}=\operatorname{frac}(1-h) n_{t}^{-}+\operatorname{frac} h n_{t}^{+} .
$$

Again, the number of agents can be traced back to the number of optimists and pessimists in the underlying market, to their rules of behavior and to the 'systemic hedge ratio'. Hence also the risk factors of the underlying market, in particular situations, where the interaction of the agents leads to price im- and explosions, are taken into account. Nevertheless, other risk factors known from the IMM, like equity price, volatility and interest rate risk are not neglected, because derivatives fundamental traders still use the Black-Scholes formula to detect arbitrage opportunities. From the dynamics of the other types of agents it is straightforward to obtain the number of derivatives fundamental traders:

$$
\#\{d f\}_{t}=\operatorname{frac} N-\left(\#\{d l\}_{t}+\#\{d s\}_{t}\right) .
$$

Note that the selected design is geared to the dimensions of option trading as they are described by Lakonishok et al. (2007) in their comprehensive exploration of investor behavior in the option market. On the one hand, it is distinguished between long and short positions. On the other hand, the purpose of investment - hedging or speculating - is taken into account directly. Finally some of their results point towards trend-chasing, which, based on the majority opinion in the underlying market, is also integrated in the model.

Before turning to option prices derived from the agents' dynamics, it is necessary to explain how many contracts the VaR computation in the option market includes. ${ }^{36}$ Like

\footnotetext{
${ }^{36}$ W.l.o.g. we assume an exchange ratio of $1: 1$ but this has nothing to do with the portfolio one is inter-
} 
in the stock market this paper considers risk from only one asset in the derivatives market, i.e. from one call option. In the case of the stock, price paths of 250 trading days in line with the Basel framework have been simulated, while the call option matures after 30 days. That is why an arbitrary point in time has to be chosen, where the call starts to run. ${ }^{37}$ It could be recommended that it would be more advantageous to consider a revolving portfolio of options. However, we decide in favor of simplification since the presented design should already clarify that the IMM neglects parts of the systemic risk the agent-based model is able to capture - independent on what market one trades. ${ }^{38}$

\subsubsection{Fundamental and Market Price Process}

After knowing the agents' dynamics and the transformation process in the stock market, it is straightforward to determine the expected excess demand in the option market. Here the EED of noise traders is defined by

$$
E E D_{t}^{n_{c}}=(\#\{d l\}-\#\{d s\}) \operatorname{vol}_{\text {mod }}
$$

Again fundamentalists start trading, if they recognize arbitrage opportunities. Thus the expected excess demand generated by the derivatives fundamental traders looks similar to equation (14):

$$
E E D_{t}^{f_{c}}=\frac{c_{t}^{f}-c(t)}{c(t)\left(1+\hat{r}_{M}\right)} \#\{d f\} v l_{\text {mod }} .
$$

As previously mentioned the fundamental call price $c_{f}$ is determined by the Black-Scholes formula. Out of construction the special case of $h=0.5$ leads to an identical number of derivatives long and short noise traders. That is why in this case the call price is mainly driven by Black-Scholes formula and depends on the market price of the agent-based model and its other risk factors. ${ }^{39} \mathrm{But}$, in order to emphasize the impact of requiring a minimum level, we concentrate on $h=0.25$ and $h=0.75$. Depending on the underlying it is hard to say that these numbers are far from reality.

ested in. One reason for the selected design is that we do not have to deal with the missing subadditivity of the VaR.

${ }^{37}$ In fact this explains slightly different starting values. But note that the number of simulations is equal to 50000 for each asset - independent on what market one trades.

${ }^{38} \mathrm{In}$ practice, the question would not arise since risks from all financial instruments at least of the trading book have to be simulated.

${ }^{39}$ Volatilities and interest rates are the same as in the case of the IMM. 


\subsubsection{Feedback}

It is a matter of common knowledge that derivatives do not only represent risky investments in their own market, but can also produce a risk increasing feedback on the underlying market. Otherwise the fear of the so-called triple witching hour, where simultaneously three kinds of derivatives expire, would be unfounded. Regrettably such spillover-effects are usually only considered with stress-tests. We will argue that it is possible to include the spill-over effect into the risk calculating model. At this juncture the systemic hedge ratio plays an important role.

In our model, feedback to the underlying is determined by the final payoff $C(T)=$ $\max (S-K, 0)$. Hence we differ two possible cases. First

$$
(S-K)^{+}>0 .
$$

From risk management perspective, the most relevant feedback is cyclical. Equation (24) reveals a bullish market. Additional demand arises when the speculative part of derivatives short traders have to deliver the stock they do not own - similar to a situation arising from short-selling the underlying. This leads to an additional excess demand in the amount of

$$
E E D_{T_{\text {call }}}^{\text {call } \rightarrow \text { stock }}=\left(\operatorname{frac}(1-h) n_{T_{\text {call }}^{-}}^{-}+\left(E E D_{T_{\text {call }}^{-}}^{f_{c}}\right)\right) .
$$

In the second case the option will not be exercised, i.e.

$$
(S-K)^{+}=0 .
$$

Again, the most relevant feedback is cyclical. Equation (26) reveals a bearish market. Less demand arises when the speculative part of derivatives long traders have to sell stocks in order to rebalance their budget. Note the asymmetry of the payoff function. Thus losses only arise to the extent of the option premium. This leads to a lower excess demand ${ }^{40}$ in the amount of

$$
E E D_{T_{\text {call }}}^{\text {call } \rightarrow \text { stock }}=-\frac{c(t=1)}{p\left(T_{\text {call }}\right)}\left(\operatorname{frac}(1-h) n_{T_{\text {call }}^{-}}^{+}+\left(E E D_{T_{\text {call }}^{-}}^{d f}\right)\right) .
$$

Summing up, the total expected excess demand of the stock in $T_{\text {call }}$ is then given by

$$
E E D_{T_{\text {call }}}=E E D_{T_{\text {call }}}^{n}+E E D_{T_{\text {call }}}^{f}+E E D_{T_{\text {call }}^{\text {call }} \rightarrow \text { stock }}^{\text {. }} .
$$

\footnotetext{
${ }^{40}$ Under certain conditions - in a concrete manner, if the Black-Scholes formula anticipates the final payoff very well - the derivative fundamental trader can lower the spill-over effect. But again this shows the limits of arbitrage, since it does not always work.
} 
Overall, this captures the realistic fact that derivatives can amplify turbulences on the underlying market. The crucial point is: The lower the systemic hedge ratio, the higher the spill-over effect can be.

\subsubsection{Risk Factors and Simulation Results}

Like in the stock market, main risk factors arise from the interaction of the agents, especially when behavioral rules, such as the extrapolation of the actual trend or herding behavior, lead to price im- and explosions (bubbles). The fact that the same can also happen in the option market is well described by Lakonishok et al. (2007). Subordinated risk factors are linked to the fundamental price process. These are the ones captured by the Black-Scholes formula.

Figures 11 - 14 show the results of agent-based risk calculation in the option market. In the simulation for the time before the crisis no remarkable anomaly can be found, in the simulation for the time during the crisis this concerns two price paths. As a basic principle of our model, agents involved in the option market are also dealing with stocks. ${ }^{41}$ Thus it is not surprising that we find similar results:

For the asset presented in this section the increase in VaR from -4.06 (before the crisis) to -4.70 (during the crisis) is due to the fact that the number of price paths with anomalies increases. Hence we do not obtain a counter-cyclical development in contrast to the other two assets, for which VaR results can be looked up in table 1. Once again, VaR results are at a significantly higher level than with the IMM. In the important case of the time before the crisis the agent-based value-at-risk - if already imbedded into the regulatory framework - would have caused a closer alignment of business strategy.

When looking at the different price paths, one can also draw similar conclusions about the validity of the efficient-market hypothesis as in section 4.1. Not each, but several price paths produce a bubble which truely reflects the fact that market-efficiency in general, but not automatically for a short-term sub-period is a fallacious hypothesis.

\footnotetext{
${ }^{41}$ Note that the simulations for both markets interact.
} 


\section{Simulation before the Crisis for a call on A1EWWW}
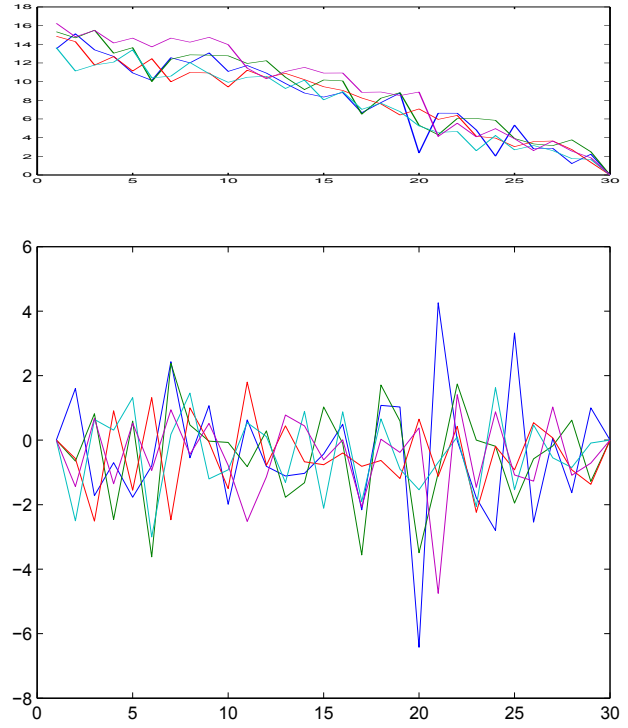

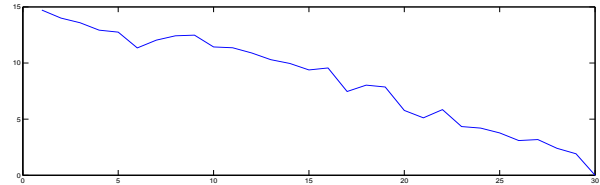

Figure 11: Simulated option price paths (top left), the corresponding returns (bottom left) and the average path (top right) based on the sample 2007M1-2007M12 as well as on a 30 days maturity. In none of the five ABA simulations a bubble arises. Volatilities and interest rates are the same as in the case of the IMM. The ABA results in a $V a R=-4.06$

Simulation before the Crisis for a call on A1EWWW
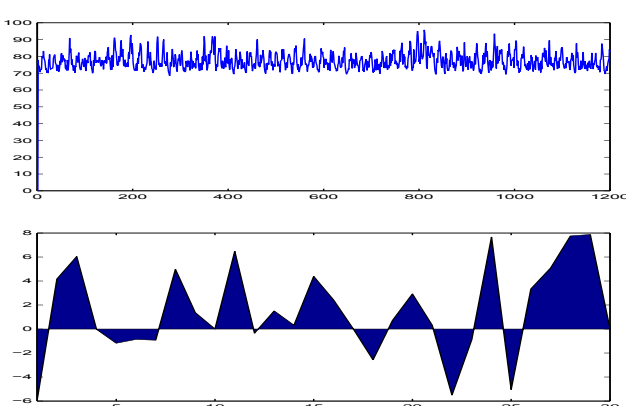
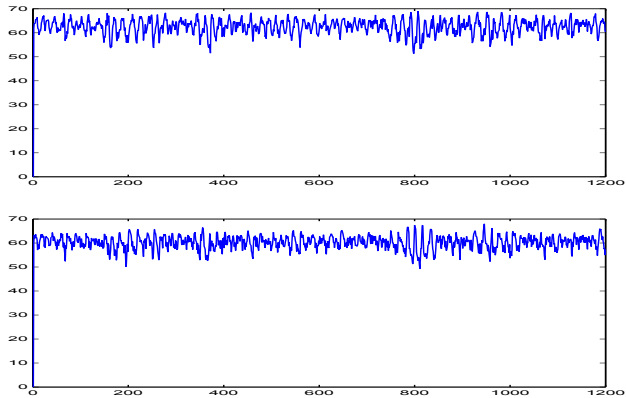

Figure 12: Agents' dynamics for one of the simulated price paths. As illustrated in figure 11 none of the ABA simulations produced a bubble. In this case, the returns of the fundamental price process (lower left sub-figure) look quite similar to the ones of the market price process (lower left sub-figure, figure 11). Similar regularities can be found in the top left sub-figure for the dynamics of the derivatives fundamentalist, in the top right for the derivatives long noise and in the bottom right for the derivatives short noise trader. 
Simulation in the Crisis for a call on A1EWWW
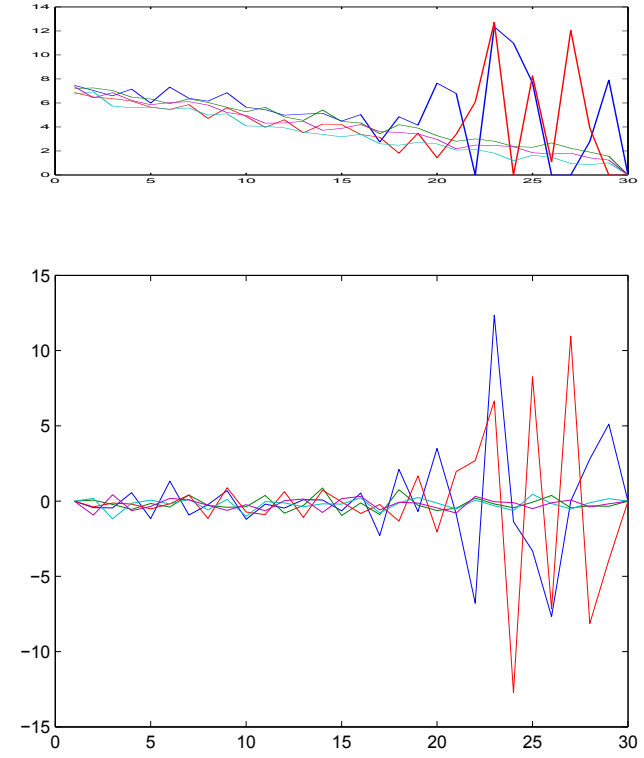

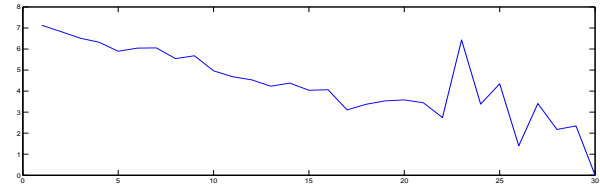

Figure 13: Simulated option price paths (top left), the corresponding returns (bottom left) and the average path (top right) reflecting the origination of a bubble in two of the ABA simulations. As in the case of the IMM, simulations are based on sample 2008M12008M12, on a 30 days maturity and on the same volatilities and interest rates. Overall the ABA results in a $\operatorname{VaR}=-4.70$.

\section{Simulation in the Crisis for a call on A1EWWW}
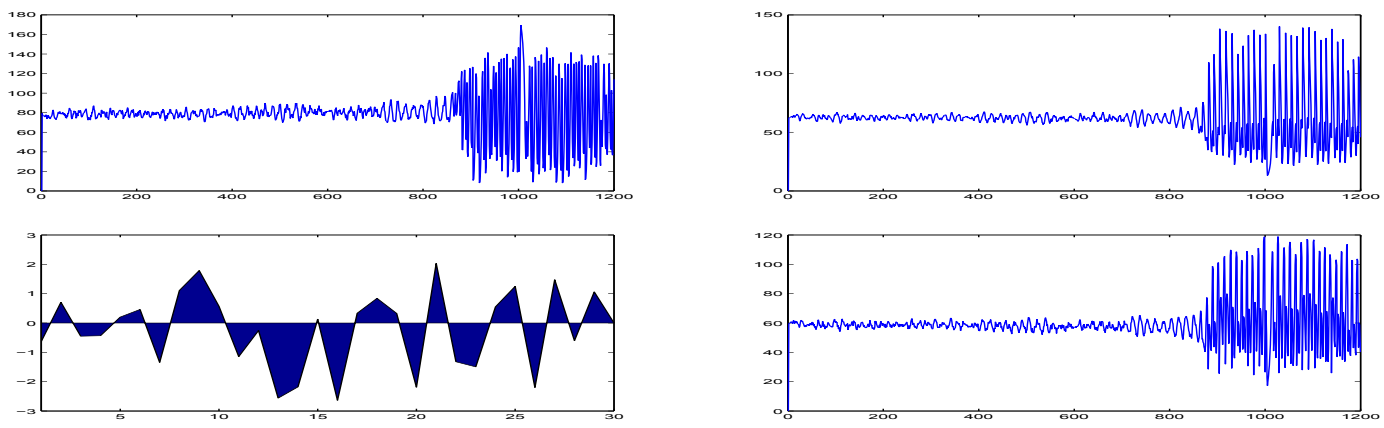

Figure 14: Agents' dynamics for one of the simulated option price paths, namely the one that embodies the origination of one of the bubbles mentioned in figure 13. For the meaning of each sub-figure compare the caption of figure 12. Note again that not each agent-based price path produces a bubble which truely reflects the fact that market-efficiency in general, but not automatically for a short-term sub-period is a fallacious hypothesis. 


\section{$5 \quad$ Policy Implications}

\subsection{Capital Requirements}

Table 1 summarizes the values-at-risk of the previous sections and adds results for two other assets. Two issues are striking. Firstly the ABA-VaR is higher than the IMM-VaR in eleven out of twelve cases. This points to a tightening of capital requirements, as the regulatory authorities currently try to install it. Secondly, in cases where VaR declines are recorded, the ABA-VaR decreases much stronger than the IMM-VaR. Taken as a whole, the ABA-values-at-risk turn out to be more countercyclical - at least when measuring the absolute portfolio change in value as if the values-at-risk represented realized losses.

These findings are largely consistent with the proposals on financial market regulation, as they were summarized in the introduction from the paper by Horn et al. (2009). Apparently, not all risks have been backed by equity so far. The agent-based model provides a way to quantify the neglected part of risks connected with crises and its resulting capital requirements are shaped in a counter-cyclical manner. If such a risk assessment is installed, systemic risk will be measured directly in the most developed parts of the Basel framework. These are the risk management models linked to the first pillar of Basel II.

\subsection{Systemic Hedge Ratio}

Usually the (micro) hedge ratio stands for the derivative contracts that are necessary to safeguard a certain amount of the underlying against losses from price fluctuations. For instance this can be (dynamically) calculated by

$$
\frac{\text { hedge amount }(t)}{\text { price underlying }(t)} \text { exchange ratio } \frac{1}{\Delta_{(t)}} \text {. }
$$

In contrast, the presented systemic hedge ratio stands for the fraction of all derivative contracts in the market which are used for hedging. It is argued that the ratio can be monitored by regulatory authorities through requiring a minimum threshold. One way of (institutional) implementation would be shifting the OTC transactions into the regulated market (stock exchange), which corresponds to proposal (4) by Horn et al. (2009) and to the intention to create centralized Designated Clearing Organizations (DOCs), see Chappe and Semmler (2012). 


\begin{tabular}{lccr}
\hline Value at Risk (VaR) & IMM standard approach & Agent-based approach & Maximum \\
\hline sample 2007M1 - M12 & $-1.70(\mathrm{~A} 1 \mathrm{EWWW})$ & -3.04 & $-3.04 \mathrm{ABA}$ \\
stock market & $-2.99(514000)$ & -11.00 & $-11.00 \mathrm{ABA}$ \\
& $-6.23(766403)$ & -7.25 & $-7.25 \mathrm{ABA}$ \\
\hline sample 2008M1 - M12 & $-1.65 \rightarrow$ & $-4.29 \nearrow$ & $-4.29 \mathrm{ABA}$ \\
stock market & $-2.11 \searrow$ & $-3.39 \downarrow$ & $-3.39 \mathrm{ABA}$ \\
& $-3.19 \downarrow$ & $-2.33 \downarrow$ & $-3.19 \mathrm{IMM}$ \\
\hline sample 2007M1 - M12 & $-2.33(\mathrm{Call} \mathrm{A1 \ldots )}$ & -4.06 & $-4.06 \mathrm{ABA}$ \\
derivatives market & $-3.27(\mathrm{Call} 51 \ldots)$ & -9.82 & $-9.82 \mathrm{ABA}$ \\
& $-8.30(\mathrm{Call} 76 \ldots)$ & -8.59 & $-8.59 \mathrm{ABA}$ \\
\hline sample 2008M1 - M12 & $-1.04 \searrow$ & $-4.70 \rightarrow$ & $-4.70 \mathrm{ABA}$ \\
derivatives market & $-0.87 \downarrow$ & $-3.27 \downarrow$ & $-3.27 \mathrm{ABA}$ \\
& $-1.61 \downarrow$ & $-4.09 \downarrow$ & $-4.09 \mathrm{ABA}$ \\
\hline
\end{tabular}

Table 1: Values-at-risk and their cyclical properties of different samples, markets and assets with respect to the comparison of the internal model method (IMM) and the agent-based approach (ABA). In general the ABA values-at-risk turn out to be higher and more countercyclical than the IMM ones - the latter measured by the absolute portfolio change in value as if the values-at-risk were realized. The information in brackets refers to the German Securities Number for each of the assets. The arrows plot the change of the VaR for each asset in the portfolio from the time before to the one after the financial crisis had started. Overall these findings are the basis for recommending the integration of agent-based models into the Basel regulatory framework.

Table 2 shows the values-at-risk for different systemic hedge ratios. For the majority of the assets it is hard to find a remarkable feedback from the derivatives market on the stock market. This should not be too surprising, since in the model many other effects can dominate. Indeed spill-over effects do not always occur. But in one case such an effect can be isolated. Here a higher number of market participants using the derivative for the purpose of hedging instead of speculation (a higher systemic hedge ratio) can significantly lower the value-at-risk. As discussed above (risk increasing) feedback from derivatives on the underlying market depends on the systemic hedge ratio. Thus the basic idea of requiring a minimum value for the systemic hedge ratio means to limit the fraction of speculative 


\begin{tabular}{lcc}
\hline Value at Risk (VaR) & $\begin{array}{l}\text { Agent-based approach } \\
\text { Systemic hedge ratio } \mathrm{h}=0.25\end{array}$ & $\begin{array}{l}\text { Agent-based approach } \\
\text { Systemic hedge ratio } \mathrm{h}=0.75\end{array}$ \\
\hline sample 2007M1 - M12 & $-3.04($ A1EWWW) & $-4.71 \rightarrow$ \\
stock market & $-11.00(514000)$ & $-4.59 \downarrow$ \\
& $-7.25(766403)$ & $-8.01 \rightarrow$ \\
\hline sample 2008M1 - M12 & $-4.29(\mathrm{~A} 1 \mathrm{EWWW})$ & $-4.95 \rightarrow$ \\
stock market & $-3.39(514000)$ & $-3.76 \rightarrow$ \\
& $-2.33(766403)$ & $-1.21 \rightarrow$ \\
\hline
\end{tabular}

Table 2: Values-at-risk for different systemic hedge ratios. For the majority of the assets it is hard to find a remarkable feedback from the derivatives market on the stock market, but in one case such an effect can be isolated. Here a higher number of market participants using the derivative for the purpose of hedging instead of speculation (a higher systemic hedge ratio) can significantly lower the value-at-risk. The information in parantheses refers to the German Securities Number for each of the assets. The arrows plot the change of the VaR for each asset in the portfolio from a derivatives market with a relatively low systemic hedge ratio to one with a relatively high one. Overall these findings are the basis for recommending a minimum level of the systemic hedge ratio.

transactions in the market. Details for implementation are left for future research, but the necessary condition for hedging is to possess the underlying. For elucidation of this perspective one might think of real-world incidents, where CDS were traded without owning the (government) bonds or currently where commodities are traded without owning the raw materials.

Finally, throughout this paper we deal with irrational bubbles and all the consequences for a more efficient risk management. It should be mentioned that in the literature also the occurrence of rational bubbles is discussed. This is based on Tirole (1985), who argues 'that bubbles are not inconsistent with optimizing behavior and general equilibrium'. However, this distinction does not change the fact that somebody has to bear the costs at the moment, where bubbles burst, in order to guide the economy towards the previously reached state. The question is more who you prefer - society as a whole or the financial industry, which benefits disproportionately, when these bubbles arise. This paper opts for the latter by making them internalize the external costs of a bubble. 


\section{Conclusion}

From a micro perspective the presented model recommends nothing else than internalizing the external costs of bubbles. A maximum approach, including agent-based risk calculation, is proposed to be the basis of new regulatory capital requirements (Basel IV) since we find for the ABA reasonable values-at-risk that differ both in the level as well as in the cyclical properties from existing models. These capital requirements should be demanded from all major market players, including hedge funds. From a theoretical point of view the presented model clearly recommends that the regulatory authorities should find out how many derivatives per each underlying are used for hedging, e.g. by the obligation to employ stock exchanges also as trading platforms for the Over-The-Counter products. For such a 'systemic hedge ratio' a minimum level should be required. However, based on data of the time of the financial crisis we find a significant spill-over effect from the derivatives to the stock market only in one simulation. Agent-based risk management deserves future research and leaves room for the extension to other types of financial instruments which are not covered in this paper.

\section{References}

Alexander, G. J., Baptista, A. M. and Yan, S. (2012), Bank regulation and stability: An examination of the Basel market risk framework, Discussion Paper 9/2012, Deutsche Bundesbank.

Alicke, M. D. and Govorun, O. (2005), The Better-Than-Average Effect, in 'The Self in Social Judgment', M. D. Alicke, J. I. Krueger and D. A. Dunning (Eds.), pp. 86-106. Psychology Press.

Arthur, W. B., Holland, J. H., LeBaron, B., Palmer, R. and Tayler, P. (1996), 'Asset Pricing Under Endogenous Expectations in an Artificial Stock Market', SSRNeLibrary . URL: $h t t p: / / s s r n . c o m /$ paper $=2252$

Baillie, R. T., Bollerslev, T. and Mikkelsen, H. O. (1996), 'Fractionally integrated generalized autoregressive conditional heteroskedasticity', Journal of Econometrics 74, 3-30.

Basel Committee on Banking Supervision (2010), Basel III: A global regulatory framework 
for more resilient banks and banking system, Technical report, Bank For International Settlements. December Version.

Black, F. and Scholes, M. (1973), 'The pricing of options and corporate liabilities', Journal of Political Economy 81, 637-654.

Bollerslev, T., Engle, R. F. and Nelson, D. B. (1994), ARCH Models, in 'Handbook of Econometrics', Vol. 4, R.F. Engle and D.L. McFadden (Eds.), pp. 2959-3038. Amsterdam: North-Holland.

Campbell, J. Y. and Kyle, A. S. (1993), 'Smart Money, Noise Trading and Stock Price Behavior', Review of Economic Studies 60, 1-34.

Chappe, R. and Semmler, W. (2012), Financial Reform in the U.S.: A Critical Survey of Dodd-Frank and What is Needed for Europe, IMK Studies 28.

Chen, S.-H., Lux, T. and Marchesi, M. (2001), 'Testing for nonlinear structure in an artificial financial market', Journal of Economic Behavior and Organization 46, 327342.

Colander, D., Föllmer, H., Haas, A., Goldberg, M., Juselius, K., Kirman, A., Lux, T. and Sloth, B. (2009), The Financial Crisis and the Systemic Failure of Academic Economics, Working Paper 1489, Kiel Institute for the World Economy.

Davidson, P. (1982), 'Rational Expectations: A Fallacious Foundation for Studying Crucial Decision-Making Processes', Journal of Post Keynesian Economics 5, 182-198.

DeGrauwe, P., Dewachter, H. and Embrechts, M. (1993), Exchange Rate Theory : Chaotic Models of Foreign Exchange Markets, Blackwell Cambridge.

DeLong, J. B., Shleifer, A., Summers, L. H. and Waldmann, R. J. (1990), 'Noise trader risk in financial markets', Journal of Political Economy 98, 703-738.

Dullien, S. (2012), Anspruch und Wirklichkeit der Finanzmarktreform: Welche G20 Versprechen wurden umgesetzt?, IMK Studies 26.

Fama, E. F. (1970), 'Efficient Capital Markets: A Review of Empirical Work', Journal of Finance 25, 383-417. 
Horn, G., Joebges, H., Kamp, L., Krieger, A., Sick, S. and Tober, S. (2009), Gesamtwirtschaftliche Stabilität durch bessere Regulierung - Vorschläge für eine Neuordnung der Finanzmärkte, IMK Report 36.

Kirman, A. P. (1992), 'Whom or What Does the Representative Individual Represent?', Journal of Economic Perspectives 6, 117-136.

Lakonishok, J., Lee, I., Pearson, N. D. and Poteshman, A. M. (2007), 'Option market activity', Review of Financial Studies 230, 814-857.

Lux, T. (1998), 'The socio-economic dynamics of speculative markets: interacting agents, chaos and the fat tail of return distribution', Journal of Economic Behavior and Organization 33, 143-165.

Lux, T. and Marchesi, M. (2000), 'Volatility Clustering in Financial Markets: A Microsimulation of Interacting Agents', International Journal of Theoretical and Applied Finance 3, 675-702.

Mandelbrot, B. B., Fisher, A. and Calvet, L. (1997), A Multifractal Model of Asset Returns, Cowles Foundation Discussion Paper 1164, Yale University.

Mandelbrot, B. B. and van Ness, J. W. (1968), 'Fractional Brownian Motions, Fractional Noises and Applications', SIAM Review 10, 422-437.

Merton, R. C. (1973), 'Theory of Rational Option Pricing', The Bell Journal of Economics and Management Science 4, 141-183.

Pagan, A. (1996), 'The econometrics of financial markets', Journal of Empirical Finance 3, 15-102.

Ritter, J. R. (2003), 'Behavioral finance', Pacific-Basin Finance Journal 11, 429-437.

Shiller, R. J. (2003), 'From efficient market theory to behavioral finance', Journal of Economic Perspectives 22, 83-104.

Shleifer, A. and Summers, L. H. (1990), 'The Noise Trader Approach to Finance', Journal of Economic Perspectives 4, 19-33.

Tirole, J. (1985), 'Asset Bubbles and Overlapping Generations', Econometrica 53, 10711100. 
Publisher: Hans-Böckler-Stiftung, Hans-Böckler-Str. 39, 40476 Düsseldorf, Germany Phone: +49-211-7778-331, IMK@boeckler.de, http://www.imk-boeckler.de

IMK Working Paper is an online publication series available at: http://www.boeckler.de/imk 5016.htm

ISSN: $1861-2199$

The views expressed in this paper do not necessarily reflect those of the IMK or the Hans-Böckler-Foundation.

All rights reserved. Reproduction for educational and non-commercial purposes is permitted provided that the source is acknowledged. 